\title{
Mechanical Behaviour of Duplex Phase Structures in a Medium Carbon Low Alloy Steel
}

\author{
K.K. Alaneme ${ }^{\mathrm{a}, \mathrm{b}} *$, S. Ranganathan ${ }^{\mathrm{a}}$, T. Mojisola ${ }^{\mathrm{b}}$ \\ ${ }^{a}$ Department of Materials Engineering, Indian Institute of Science, Bangalore, India. \\ ${ }^{\boldsymbol{b}}$ Department of Metallurgical and Materials Engineering, Federal University of Technology, \\ Akure, Nigeria \\ *Corresponding Author: kalanemek@yahoo.co.uk
}

\begin{abstract}
The mechanical behaviour of duplex phases produced in a medium carbon low alloy steel with potentials for use as machine body parts and vehicle panels, has been investigated. A representative composition of the steel (C: 0.3; Si: 0.28; Mn: 0.97; Cr: 0.15) was utilized to produce ferrite - martensite duplex phases of varied proportions by intercritical annealing treatment. The tensile, hardness, and rotating bending fatigue behaviour of the structures were studied; and optical and SEM microscopy utilized to characterize the microstructures and their fracture characteristics. The duplex phase structures exhibited continuous yielding behaviour; and were characterised by high strain hardenability, high tensile strength, total elongation, toughness and superior fatigue strength (endurance limit) in comparison with the normalised structure. The fatigue fracture was observed to be characterized by mixed mode of ductile (dimple) fracture and intergranular brittle cleavage for the duplex structures. Superior tensile and fatigue property combinations were better harnessed when treatment was performed at $760^{\circ} \mathrm{C}$ and $780^{\circ} \mathrm{C}$ in comparison to $740^{\circ} \mathrm{C}$.
\end{abstract}

Keywords: duplex phase steel; intercritical annealing; fatigue behaviour; microscopy

\section{INTRODUCTION}

The automobile and many other industries in the manufacturing sector are constantly in demand of steel possessing a good compromise of toughness and plasticity at high strength levels [1]. The steel grades are usually required for the production of body parts of vehicles, trucks, and machineries [1 - 3]. The steel grades commercially utilised for these applications are designed with compositions usually containing micro-alloying elements like molybdenum, niobium, 
nickel, and chromium among others, which function as strengtheners, phase stabilizers, formability enhancers [4 -6]. Intercritical annealing treatment has been adopted over the years to produce dual phase structures in these steels which consist of ferrite and martensite/bainite [7 - 9]; and have shown superior combinations of strength, toughness and plasticity over conventional high strength low alloy steels [10 - 11]. Mazinani and Poole studied deformation behaviour of martensite in a low-carbon dual - phase steel [5]; Sun and Pugh investigated the properties of thermomechanically processed dual - phase steels containing fibrous martensite [6]; $\mathrm{Xu}$ et al researched on the mechanical properties of fine-grained dual phase low - carbon steels based on dynamic transformation [10]. The findings of these researchers all point to the superior strength and plasticity characteristics of dual phase steels over conventional high strength low alloy steels. There have been also a great number of investigations on the role of martensite proportion in influencing the tensile properties of dual phase steels [7, 11, and 14].

The amenability of dual phase steels for structural load bearing and dynamic stress applications has also attracted research interest with some encouraging results [12 -13]. Tayanc et al studied the effect of carbon content on fatigue strength of dual phase steels in which they observed superior fatigue strength of the dual phase steels over the as - received samples and the limiting effect of intercritical treatment temperature was highlighted [19]. Chakraborti and Mitra (2005) studied LCF behaviour of two dual phase steels with lammelar morphology and found that the volume fraction of martensite has an influence on the fatigue behaviour [20]. Hadianfard investigated the low cycle fatigue behaviour and failure mechanism of a dual phase steel in which the effect of high strain amplitude and low strain amplitude on damage mechanism in the dual phase steel was reported [21]. But generally most investigations in fatigue characteristics of dual phase steels especially the fatigue mechanisms have generated divergent opinions judging by the research findings of most researchers [19]. The present work is an effort to improve the tensile and fatigue strength of a medium carbon low alloy steel grade with potentials for use as engine seat and bumper protectors, and also for machine body parts. The working conditions are such that the parts are often subjected to static and dynamic stresses which make quasi static (tensile) and fatigue stress considerations crucial for investigation if the use of the steel grade among other choice materials is to be endorsed. A representative chemical composition of the steel grade is used as test material for this research work.

\section{MATERIALS AND METHODS}

The material for the investigation is a medium carbon low alloy steel as-supplied as cylindrical rods of $16 \mathrm{~mm}$ diameter. Chemical analysis to determine the composition of the steel was performed spectrometrically. The chemical composition (in wt \%) is as follows: C (0.3); $\mathrm{Si}$ (0.28); Mn (0.97); P (0.0341); S (0.0021); Cr (0.15); Ni (0.035); Mo (0.0034); V (0.0012).

The rods were initially subjected to normalizing treatment to annul the thermal and mechanical history of the steel. The normalizing treatment was carried out at $860^{\circ} \mathrm{C}$ for one hour in a muffle 
furnace and then cooling in air. Cold rolling of the rods to approximately $50 \%$ of the original diameter $(8 \mathrm{~mm})$ was carried out before intercritical treatment was performed by first determining the lower critical temperature $\left(\mathrm{Ac}_{1}\right)$ and the upper critical temperature $\left(\mathrm{Ac}_{3}\right)$ for the test material following empirical relations in accordance with Gorni [15]. The test pieces were then treated at intercritical temperatures of $740^{\circ} \mathrm{C}, 760^{\circ} \mathrm{C}$, and $780^{\circ} \mathrm{C}$; and were held for 30 minutes, followed by quenching rapidly in oil to avoid the development of quench cracks which arise with the use of water quenching for the above composition. Control samples were prepared by normalising a set of the cold rolled samples at $860^{\circ} \mathrm{C}$ for 30 minutes and then air cooling.

\subsection{Hardness and Tensile Testing}

The macro hardness of the specimens was evaluated using a Rockwell Hardness Tester using a 'C' scale (HRC). The specimen surfaces were initially polished using emery papers and diamond - ethanol suspension to ensure a smooth surface is produced to allow for reliable determination of the hardness values; also three - four repeat tests were performed on each specimen and the average taken as representative of the hardness attained for the corresponding treatment.

The tensile testing was performed at room temperature using a universal tensile testing machine. Tensile test was performed using standard specifications in accordance with the ASTM E8M 91 standards [16]. The test was conducted on round specimens having a gage diameter of $5 \mathrm{~mm}$ and gage length of $27 \mathrm{~mm}$. All tests were performed at room temperature and at a quasi - static strain rate of $10^{-3} / \mathrm{s}$. Multi tests where performed for each treatment to ensure reliability of the data generated.

\subsection{Fatigue Tests}

Fatigue tests were performed using a cantilever - type rotating bending fatigue testing machine operated at $50 \mathrm{~Hz}$ and 3000R.P.M. The fatigue specimens were prepared in accordance with standard procedures having standard configurations of $5 \mathrm{~mm}$ internal diameter, $6 \mathrm{~mm}$ outer diameter, and 6omm gauge length. Polishing prior to testing to achieve a smooth surface which helps eliminate any potential surface discontinuity was carried out. Bending moments where applied to each specimen and the number of cycles required to fracture the specimen was recorded. The applied moment was continually reduced for successive specimens and the corresponding cycles to failure recorded until a stress (moment) threshold was observed (after $10^{8}$ Cycles) and no sign of crack initiation. The corresponding stress for each applied moment was obtained by using the empirical relation -

$\mathrm{S}=32 \mathrm{M} / \Pi \mathrm{d}^{3}$

Where, $\mathrm{S}=$ Stress amplitude $(\mathrm{MPa}), \mathrm{M}=$ bending moment $(\mathrm{N}-\mathrm{m})$, and $\mathrm{d}=$ diameter of the specimen (mm). 


\subsection{Metallography and Fractography}

The microstructural investigation was performed using a ZEISS Axiovert 200MAT optical microscope. The specimens for the optical microscopy were polished using a series of emery papers of grit sizes ranging from $500 \mu \mathrm{m}-1500 \mu \mathrm{m}$; while fine polishing was performed using polycrystalline diamond suspension of particle sizes ranging from $10 \mu \mathrm{m}-0.5 \mu \mathrm{m}$ with ethanol solvent. The specimens were etched with $2 \%$ Nital solution for between 5 - 10 seconds before observation in the optical microscope.

Fractography analysis of the fatigue fractured specimen surfaces was performed using a SERION scanning electron microscope with the Secondary electron imaging performed using an applied voltage of $15 \mathrm{KV}$.

\section{RESULTS AND DISCUSSION}

\subsection{Heat-Treatment and Microstructure}

Figure 1 show the microstructures developed from the intercritical treatment performed at $740^{0}$, $760^{\circ}$, and $780^{\circ} \mathrm{C}$. From the micrographs, it is observed that the individual microstructures consist essentially of ferrite (gray phase) and martensite (dark phase) but with varying volume fractions of martensite. The volume fractions of martensite were estimated using Sigma scan pro image analyzing software; and volume fractions of 36, 68 and $80 \%$ were obtained respectively for the $740^{\circ}, 760^{\circ}$, and $780^{\circ} \mathrm{C}$ intercritical treatments.

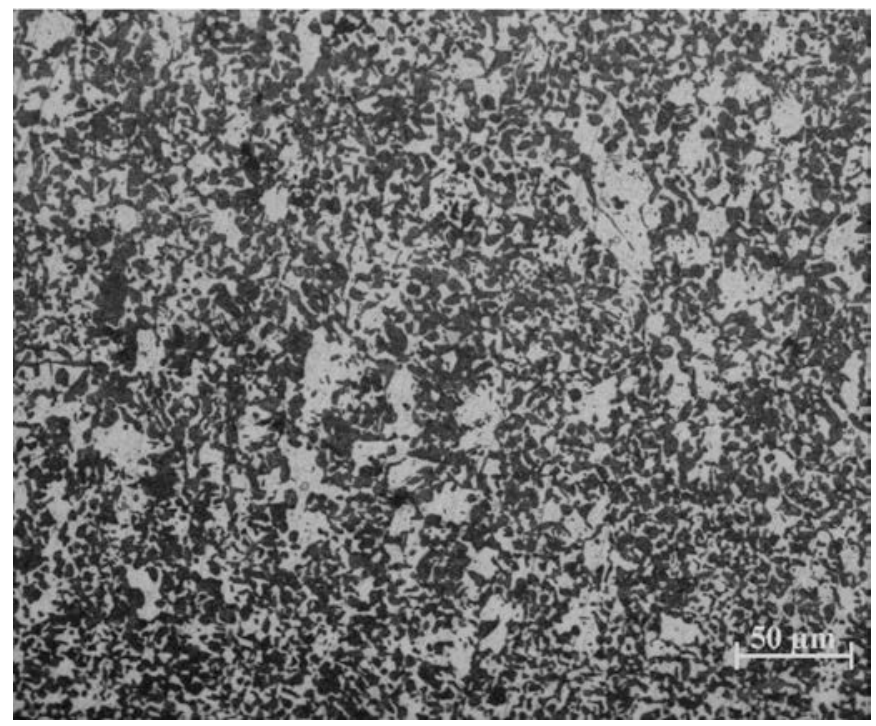

Figure 1(a) Duplex Phase structure produced by intercritical Annealing at $740^{\circ} \mathrm{C}$ for 30 minutes then water quenching. The structure reveals a large proportion of ferrite (gray phase) and martensite (dark phase) 


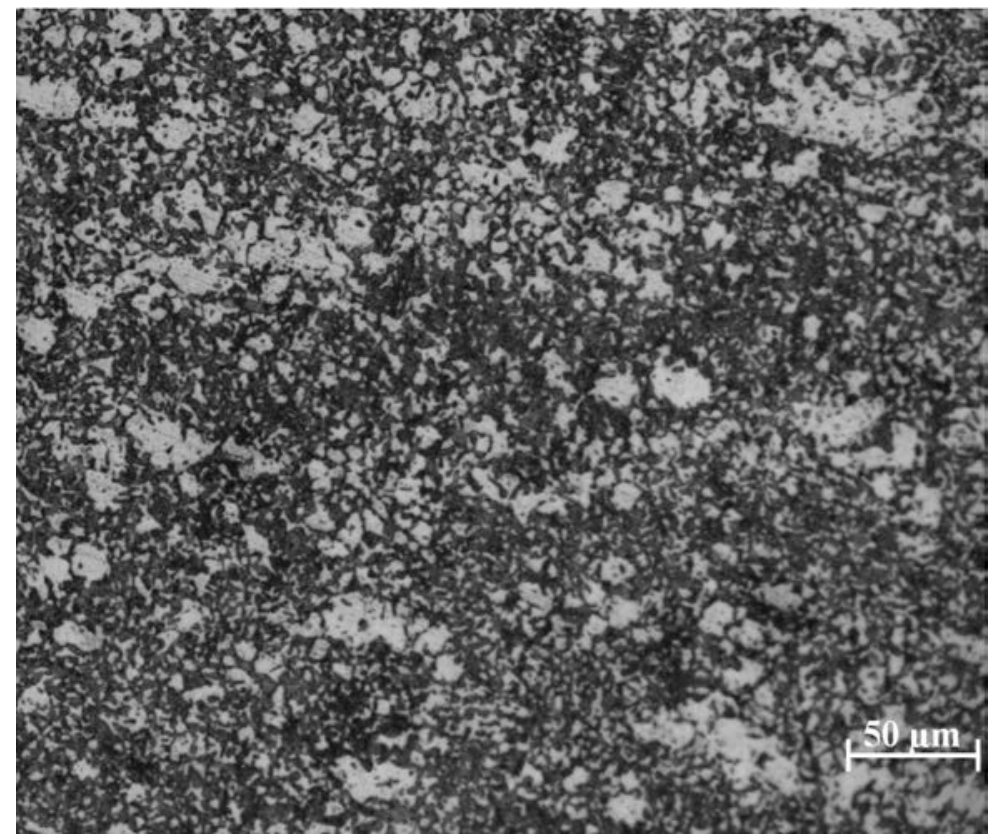

Figure 1(b) Duplex Phase structure produced by intercritical annealing at $760^{\circ} \mathrm{C}$ for 30 minutes then water quenching. The structure reveals blocky and fine grain distribution of ferrite (gray phase) and martensite (dark phase)

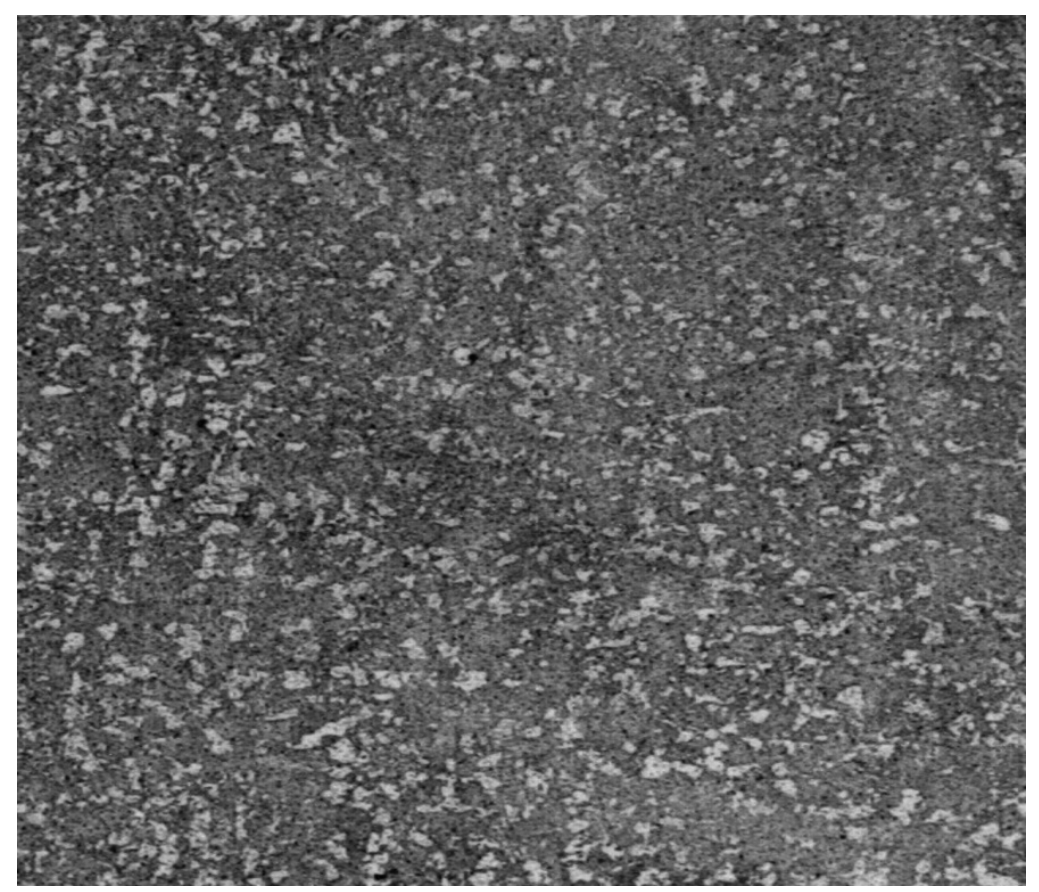

Figure 1 (c) Duplex Phase structure produced by intercritical annealing at $780^{\circ} \mathrm{C}$ for 30 minutes then water quenching. The structure reveals medium - sized and fine grain distribution of ferrite (gray phase) and a large proportion of martensite (dark phase) 


\subsection{Tensile Properties}

Figures 2 and 3 show the engineering stress -strain and true stress - strain curves for the duplex phase structures produced by treating at $740^{\circ}, 760^{\circ}$, and $780^{\circ} \mathrm{C}$. For the purpose of comparing stress -strain behaviour, the stress-strain profiles of conventionally heat-treated normalized structure is superimposed in the graphs. Observation of Figure 2 shows that the duplex phase structures exhibited continuous yielding typical of traditional dual phase steel compositions despite the large volume fractions of martensite especially for the $760^{\circ}$, and $780^{\circ} \mathrm{C}$ intercritical treatment which yielded 68 and $80 \%$ respectively; while the conventional normalized structure exhibited as expected - discontinuous yielding (presence of definite yield point). The continuous yielding phenomenon has been explained by Bhattacharyya et al. [14] and Park et al. [17] to be due to phase straining (plastic deformation) induced in the ferrite matrix, as a result of accommodating the volume expansions associated with the austenite to martensite transformation on quenching from the intercritical phase region. Thus when the duplex - ferrite and martensite - structure is subjected to tensile loading, plastic deformation commences immediately (plastic deformation of the ferrite continues), resulting in the continuous yielding behaviour observed in the duplex structures [18].

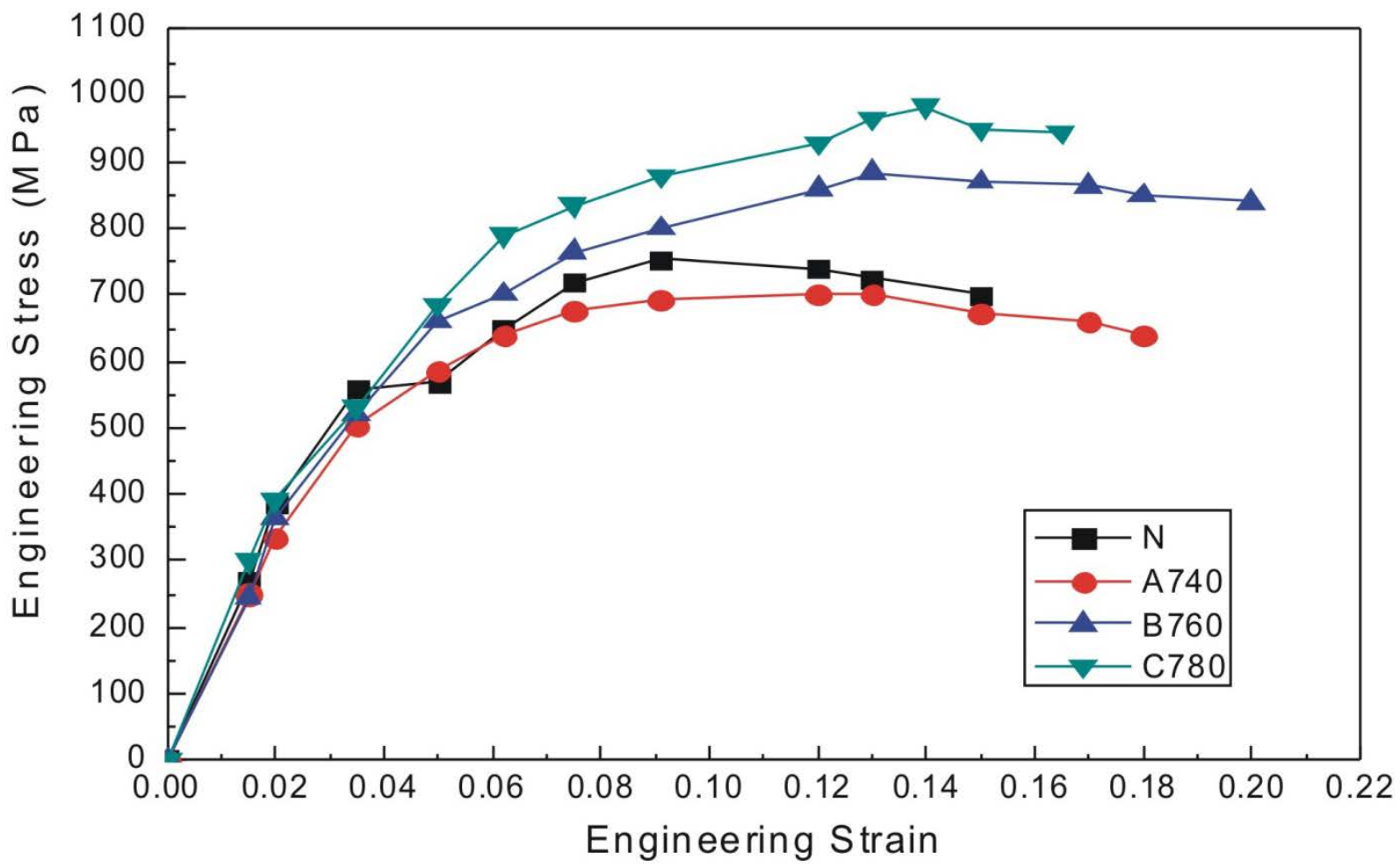

Figure 2: Engineering Stress - Strain curves of the Duplex Phase Steels 


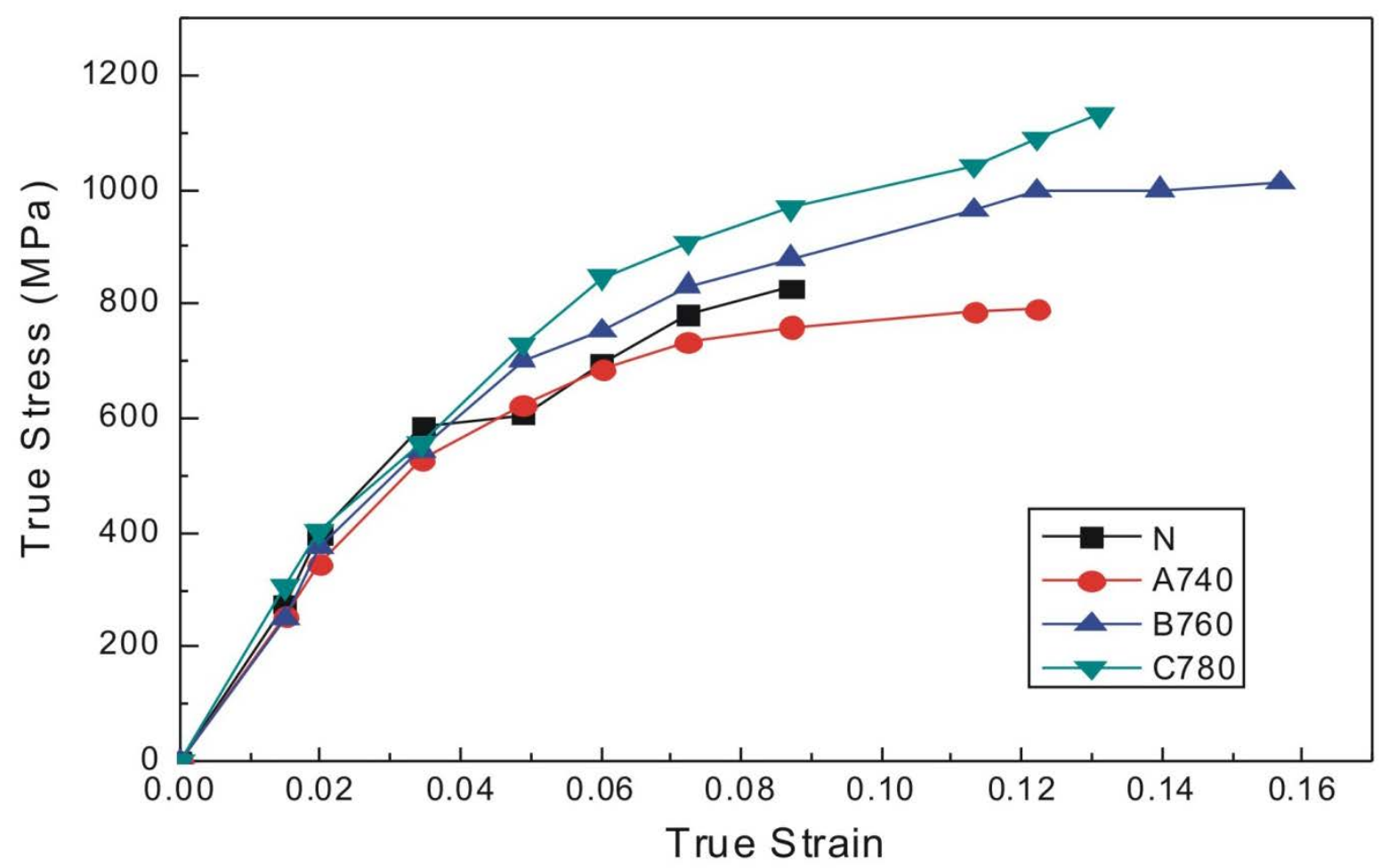

Figure 3: True Stress - Strain curves for the Duplex phase Steels

The tensile properties of the duplex phase structures are summarized in Table 1 . The yield strength and ultimate tensile strength increased with the volume percent martensite while the percent elongation for all duplex phase structures ranged between $17 \%-21.5 \%$; and were relatively higher in comparison with the conventional normalized structure which had percent elongation of $15 \%$. The increase in tensile strength and yield strength with increase in the volume percent martensite is consistent with observations of Nobuyuki [4], Sun and Pugh [6], and Kumar et al. [7]. The toughness values presented in Table 1 (estimated by calculating the area under the engineering stress - strain graph, Figure 2) revealed higher toughness values for the $760^{\circ} \mathrm{C}$ and $780^{\circ} \mathrm{C}$ intercritical treatment (B760 and C780) which is consistent with the large volume fractions of martensite. The conventionally normalised specimen is observed to possess the least toughness. The generally improved toughness observed in the duplex phase structures is attributed to the composite structure of ferrite and martensite which creates a synergy of the soft ferritic phase and the hard martensitic phase, which helps in increasing the materials resistance to crack propagation and fracture [18]. 
Table 1: Tensile Properties of the Duplex Phase structures

\begin{tabular}{|l|l|l|l|l|l|}
\hline $\begin{array}{l}\text { Sample } \\
\text { Designation }\end{array}$ & $\begin{array}{l}\text { Volume } \\
\text { Fraction } \\
\text { Martensite, } \\
\mathrm{V}_{\mathrm{m}}(\%)\end{array}$ & $\begin{array}{l}\text { Ultimate } \\
\text { Tensile } \\
\text { Strength, } \\
\sigma_{u}(\mathrm{MPa})\end{array}$ & $\begin{array}{l}\text { Yield } \\
\text { Strength, } \\
\sigma_{y} \text { (MPa) }\end{array}$ & $\begin{array}{l}\text { Strain to } \\
\text { failure, } \varepsilon_{f} \\
(\%)\end{array}$ & $\begin{array}{l}\text { Toughness } \\
\left(\mathrm{J} / \mathrm{m}^{3}\right)\end{array}$ \\
\hline $\mathrm{A} 740$ & 36 & 702 & 530 & 18 & 106.35 \\
\hline B760 & 68 & 884 & 585 & 22 & 125.5 \\
\hline C780 & 80 & 984 & 680 & 17 & 129.6 \\
\hline $\mathrm{N}$ & - & 754 & 560 & 16 & 83.55 \\
\hline
\end{tabular}

\subsection{Fatigue Properties}

Figure 4 shows the $\mathrm{S}-\mathrm{N}$ curves for the duplex phase structures and the conventional normalized specimen. From the graph it is seen that the three duplex phase structures had fatigue strengths superior to that of the normalized samples. This trend is similar to the observations of Alzari et al [22], Nakajima et al [23], Alp and Wazzan [24]. The plot also reveals that the specimens treated at $760^{\circ} \mathrm{C}$ had the highest endurance limit (247MPa) while the specimens treated at $780^{\circ} \mathrm{C}$ and $740^{\circ} \mathrm{C}$ had correspondingly lower endurance limits of $232 \mathrm{MPa}$ and $225 \mathrm{MPa}$ respectively. This indicates that the fatigue strength of the dual phase steels increases with increasing martensite content to a limit of approximately 68\% martensite beyond which further increase in martensite content yields a decrease in fatigue strength as observed for the case of the $780^{\circ} \mathrm{C}$ treated samples with $80 \%$ martensite. The increase in fatigue strength observed at higher intercritical temperatures is attributed to tougher martensites formed at higher intercritical temperatures, due to the lower carbon content of the martensite formed at higher intercritical temperatures to obtain higher volume percentages of martensite [25]. Tayanc [19] noted that increasing volume fraction of martensite lowers the ductility of the duplex phase steels and leads to a decrease in the fatigue life. Also they noted that the fatigue life is a function of the strain distribution between the ferrite and martensite components of the duplex phase steels which influences crack initiation and growth. The SEM fractographs in Figure 5 show that the fatigue fracture mode is a mixed mode consisting of ductile (dimple) fracture and intergranular brittle cleavage. Figure 5a shows that the proportion of ductile dimple features is higher for the $760^{\circ} \mathrm{C}$ in comparison to the $780^{\circ} \mathrm{C}$ Figure 5(b), which could account for the relatively higher fatigue strength achieved for the $760^{\circ} \mathrm{C}$ series. The ductile dimples arise from the ferritic grains while the intergranular cleavage facets emanates from the martensitic grains. Fatigue cracks are known to propagate at a faster rate in brittle structures in comparison to more ductile structures -thus it can be argued that in the duplex phase steels there will be more crack deflection, and branching in the more ductile duplex phase structures at the ferrite - martensite interfaces leading to reduced fatigue crack growth rate [19]. 


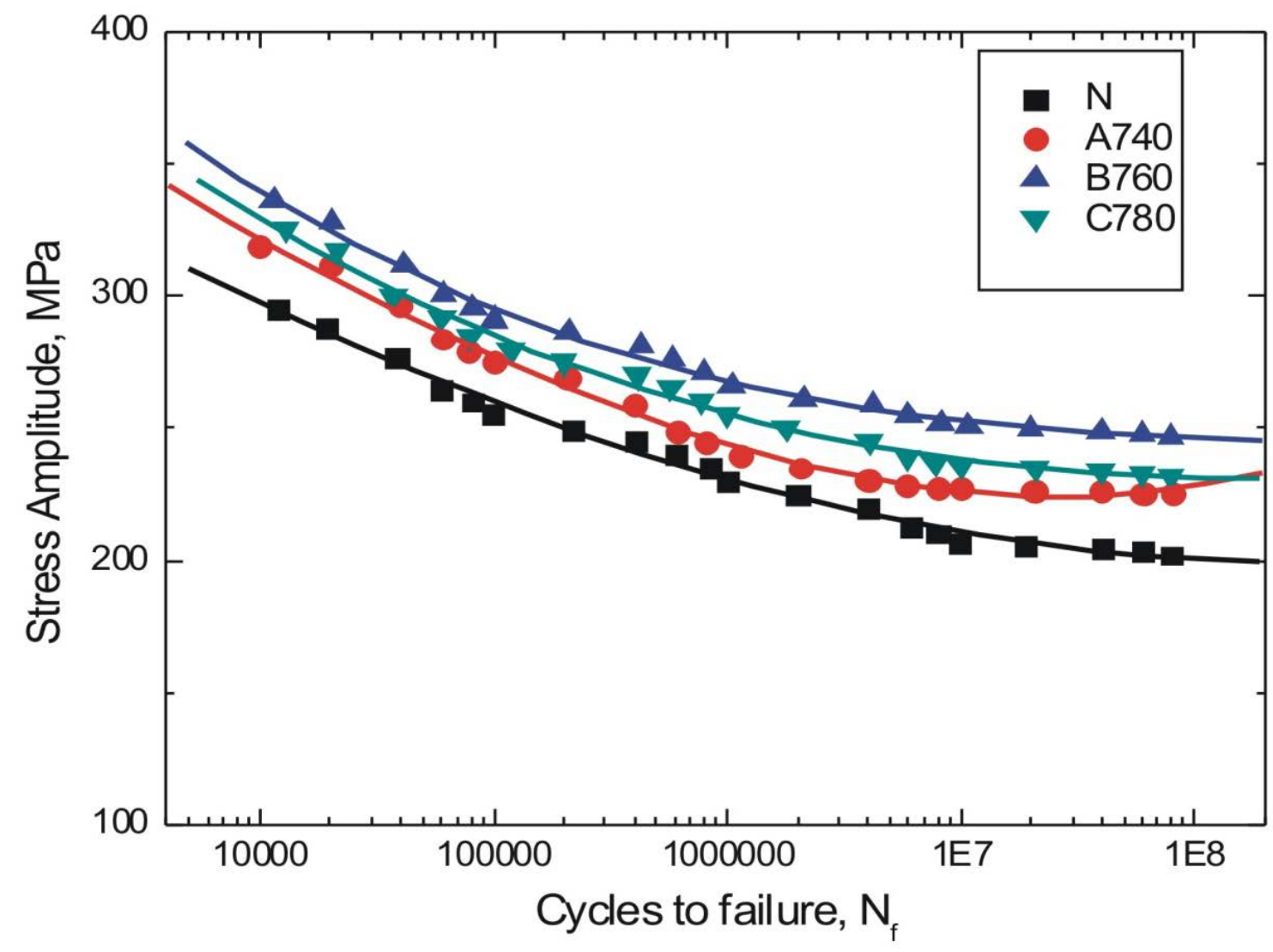

Figure 4: S - N Curves for the Duplex phase steels 


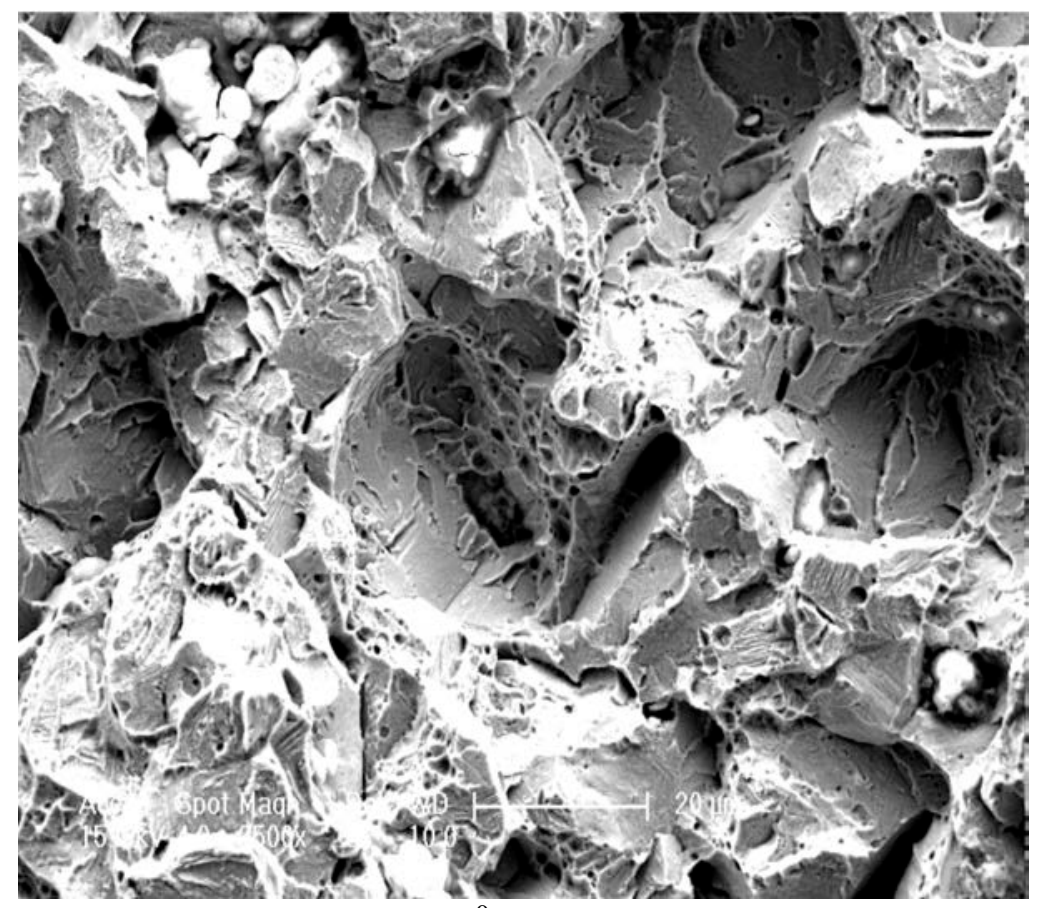

Figure 5(a): Fatigue fractograph of the $760^{\circ} \mathrm{C}$ showing mixed fracture mode comprising of ductile (dimple - like features) and intergranular brittle facets of martensitic grains

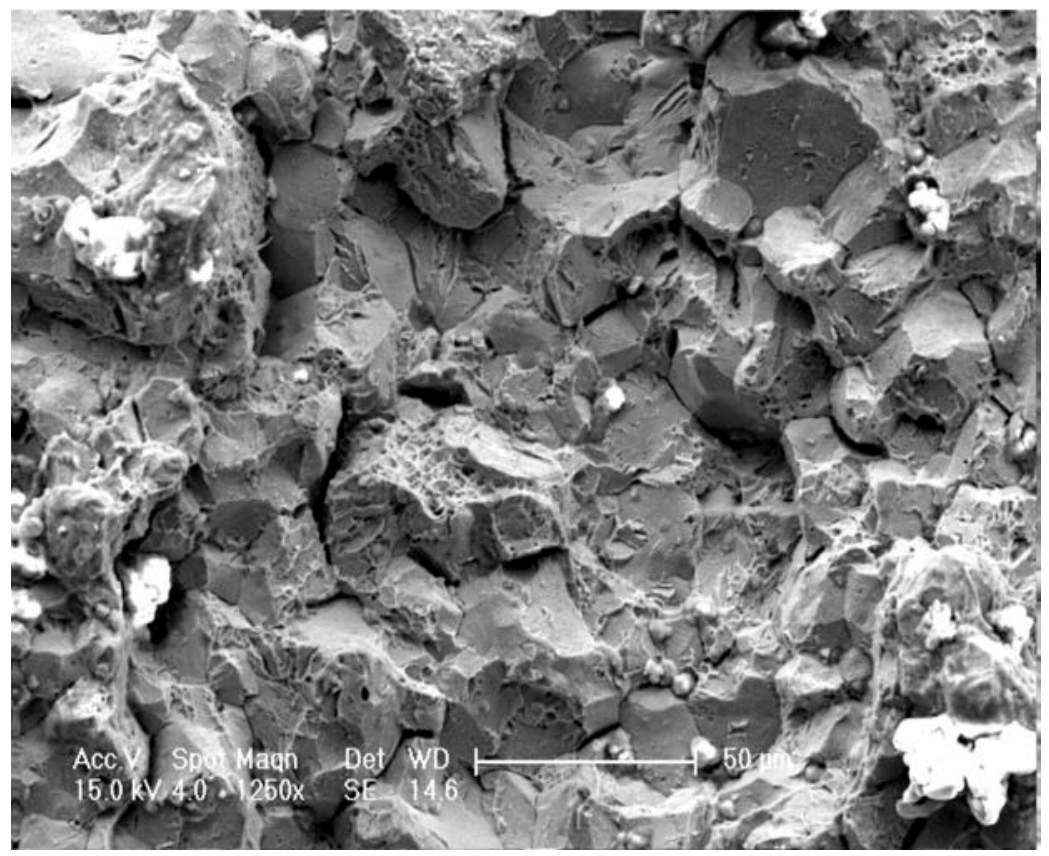

Figure 5 (b): Fatigue fractograph of the $780^{\circ} \mathrm{C}$ showing predominant intergranular facets of martensitic grains and sparse distribution of ductile dimple - like ferritice grains indicative of mixed mode of fracture. 
Overall, it is observed that the best combination of tensile strength, yield strength, total elongation, toughness, and fatigue strength (endurance limit) is obtained when treatment is performed at $760^{\circ} \mathrm{C}$ and $780^{\circ} \mathrm{C}$ for 30 minutes before water quenching. Thus tensile properties and fatigue resistance can be effectively enhanced for the carbon steel grades by the adoption of this processing heat-treatment condition which makes it suitable for high strength and structural applications.

\section{CONCLUSIONS}

The medium carbon low alloy steel with duplex phase structures consisting of ferrite and martensite exhibited continuous yielding behaviour typical of traditional dual phase steel compositions; and were interestingly characterised by high strain hardenability, high strength, total elongation, toughness and superior fatigue resistance (endurance limit) in comparison with the normalised structure which is representative of one of the more frequently utilised microstructures for the carbon steel composition. These promising tensile and fatigue property combinations were better harnessed when treatment was performed at $760^{\circ} \mathrm{C}$ and $780^{\circ} \mathrm{C}$ in comparison to $740^{\circ} \mathrm{C}$. The fatigue fracture mechanism was observed to be mixed mode of ductile (dimple) fracture and intergranular brittle cleavage.

\section{ACKNOWLEDGEMENT}

The lead author is grateful to the Association of commonwealth Universities (ACU) for the award of its prestigious Wington Titular Fellowship in Engineering which made it possible for him to perform a substantial part of this research at the Department of Materials Engineering, Indian Institute of Science, Bangalore, India. The mentoring of Prof. U. Ramamurty and Prof. S. Ranganathan throughout my stay in India is immensely appreciated.

\section{REFERENCES}

[1] M. Yano, S. Kitamura, T. I. Harashima, T. Inomoto, K. Azuma, and H. Nagahama, Recent Advances in Ultra low - Carbon Steel Refining Technology by Vacuum Degassing Processes, Nippon Steel Technical Report, No. 61, UDC 669 (1994) 18 - 982.

[2] B. Gajda, A. K. Lis, Intercritical Anealing with Isothermal Holding of Trip CMnAlSi Steel, Journal of Achievements in Materials and Manufacturing, Vol. 20, Issues 1 - 2, 2007, Pp 439 - 442.

[3] J. A. Lozano, and J. T. Panta - Mesones, Evaluation of the Heat-treatment Response of a Multiphase Hot - Rolled Steel Processed by Controlled Rolling and Accelerated Cooling, Materials and manufacturing Processes, 23 (2008) 357 - 362.

[4] I. Nobuyuki, S. Nobuo, and K. Joe, Development of Ultra - High Strength Linepipes with Dual - Phase Microstructure for high Strain Application, JFE Technical Report, No. 12, 2008, Pp $15-19$. 
[5] M. Mazinani, and W. J. Poole, Deformation Behaviour of Martensite in a Low-Carbon Dual - Phase steel, Advanced Materials Research, Vols 15 - 17, (2007), Pp 774 - 779.

[6] S. Sun, and M. Pugh, Properties of Thermomechanically processed Dual - Phase Steels containing fibrous Martensite, Materials Science and Engineering A, Vol. 335, Issues 1 2 (2002) Pp 298 - 308.

[7] A. Kumar, S. B. Singh, K. K. Ray, Influence of bainite/Martensite - content on the tensile properties of low carbon dual phase steels, Materials Science and Engineering A, 474 (2008) 270 - 282.

[8] K. Spencer, J. D. Embury, K. T. Colon, M. Veron, Y. Brechet, Strengthening via the formation of strain - induced Martensite in stainless steels, Materials Science and Engineering A, 387389 (2004) 873 - 881.

[9] A. Bayram, A. Uguz, and M. Ula, Effects of Mechanical properties of Dual - Phase Steels, Materials characterization, 43 (1999) Pp 259 - 269.

[10] H. Xu, W. Yang, and Z. Sun, Mechanical Properties of fine-grained dual phase low carbon steels based on dynamic transformation, Journal of University of Science and Technology Beijing, Mineral, Metallurgy, materials, Vol. 15, Issue 5 (2008) Pp 556 560.

[11] Y. Son, Y. K. Lee, K. T. Park, C. S. Lee, and D. H. Shin, Ultra-fine grained ferritemartensite dual phase steels fabricated via equal channel angular pressing: microstructure and tensile properties, Acta materialia, Vol. 53, Issue 11 (2005) Pp 3125 - 3134.

[12] R. S. Tripathi, R. S. Rama Rao. and S. P. Pattanaik, High Cycle Fatigue, Crack Propagation Resistance and Fracture Toughness in Ship Steels, Defence Science Journal, Vol. 51, No. 2, 2001 Pp 201 - 210.

[13] N. Rao, and A. R. Acharya, Fracture Behaviour of a High Strength medium Carbon Low Alloy Steel, Engineering Fracture Mechanics, Vol. 53, No.2, 1996 Pp 303 - 308.

[14] A. Bhattacharyya, T. Sakaki, and G. J. Weng, Influence of Martensite Shape, Concentration, and Phase Transformation Strain on the Deformation Behaviour of Stable Dual - Phase Steels, Metallurgical and Materials Transactions A, Vol. 24, No.2, (1993) Pp $301-314$.

[15] A. A. Gorni, Steel Forming and Heat treating Handbook, Vol. 2, Sao Vacente, Brazil, (2006): Pp 4.

[16] ASTM E 8M - 91: Standard test Method for Tension Testing of Metallic Materials [Metric]. In: Annual Book of ASTM Standards: ASTM International; 1992, Pp 160.

[17] K. Park, C. S. Lee, and D. H. Shin, Strain Hardenability of Ultra fine Grained low Carbon Steels Processed by ECAP, Rev. Adv. Mater. Sci (10) 2005 Pp 133 - 137.

[18] A. R. Salehi, S. Serajzadeh, and A. K. Taheri, A Study on the Microstructural changes in Hot Rolling of Dual - Phase steels, Journal of Materials Science, Vol. 41, No.7, 2006, Pp 1917 - 1925.

[19] M. Tayanc, A. Aytac, and A. Bayram, The effect of carbon on the fatigue strength of dual - phase steels, Materials and Design, Vol. 28, Issue 6 (2007) Pp 18271835. 
[20] P. C. Chakraborti, M. K. Mitra, International Journal of Fatigue 27 (5) 2005 Pp 511 518.

[21] H. J. Hadianfard, Low cycle Fatigue Behaviour and Failure Mechanism of a dual - phase steel, materials Science and Engineering A 499 (2009) Pp 493 - 499.

[22] S. Alzari, J. Morriconi, E. Brandaleze, W. Chiapparoli, G. Mansilla, S. Herenu, Practical Fatigue resistance assessment of microalloyed high strength and dual phase steels, $16^{\text {th }}$ IAS Rolling Conference, 2006, San Nicolas, Argentina, Pp 683 -690.

[23] K. Nakajima, T. Urabe, Y. hosoya, S. Kamiishi, T. Miyata and N. Takeda, Influence of microstructural morphology and prestraining on short fatigue crack propagation in dual phase steels, ISIJ International, Vol. 41 (2001), No.3, Pp 298 - 304.

[24] T. Alp, and A. Wazzan, The Influence of microstructure on the tensile and fatigue behaviour of SAE 6150 Steel, Journal of Materials Engineering and Performance, Vol. 11, Issue 4, Pp 351 - 359. DOI: 10.1361/105994902770343854.

[25] K. V. Sudhakar, and E. S. Dwarakadasa, A study on fatgue crack growth in dual phase martensitic steel in air environment, Bull. Mater. Sci., Indian Academy of Sciences, Vol. 23, No. 3, Pp 193 - 199. 